\title{
Bone dehiscences of medial orbital wall on computed tomography and assessment of terminological errors in literature
}

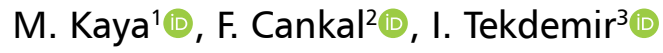 \\ ${ }^{1}$ Department of Radiology, Gazi University School of Medicine, Ankara, Turkey \\ 2Department of Anatomy, Ankara Medipol University School of Medicine, Ankara, Turkey \\ ${ }^{3}$ Department of Anatomy, Ankara University School of Medicine, Ankara, Turkey
}

[Received: 14 September 2020; Accepted: 21 December 2020; Early publication date: 22 January 2021]

\begin{abstract}
Background: The objective of this study is to investigate the position and frequency of dehiscences in the medial orbital wall and to reveal that dehiscences and orbital adipose tissue hernias are distinct entities.

Materials and methods: Two hundred-thirty medial orbital walls of 115 patients with a preliminary diagnosis of headache and sinusitis but without active ethmoidal sinusitis were examined by computer tomography in the axial plane. Two separate radiologists assessed continuity of the medial orbital wall and orbital fat tissue herniation in ethmoid cells. The medial orbital wall was divided into four quadrants and the dehiscence distribution was evaluated.

Results: Bone defects were detected in 71 (30.9\%) patients in 230 orbital medial wall reviews of 115 patients (59 males, 56 females). Eight (3.5\%) of these cases (4 male, 4 female) had herniation of the orbital adipose tissue into the ethmoid sinus. Of the 108 dehiscences, 47 were localised in the posterior upper quadrant. A statistically significant difference was found in the dehiscence distribution according to the quadrants. No significant relationship was found among age, gender, side of dehiscence and frequency of dehiscence.

Conclusions: Dehiscences in the posterior upper quadrant are more common in the medial orbital wall. Although bone dehiscences in the medial orbital wall and the herniation of the orbital fat tissue are two different entities, they are used interchangeably in most of the literature and in radiological reporting. (Folia Morphol 2022; 81, 1: 175-182)
\end{abstract}

Key words: dehiscence, herniation, medial orbital wall, computed tomography

\section{INTRODUCTION}

The bone structures that constitute the orbital medial wall are the lateral or orbital face of the lacrimal bone, the frontal process of the maxillary bone, the lamina papyracea (LP) of the ethmoid bone, and the corpus of the sphenoid bone [10]. Paranasal sinuses are air-filled spaces located within the facial and skull bones where many variations are seen [18]. Especially medial orbital wall bone structures are very thin and dehiscences are common [25]. Meloni et al. [14] re-

Address for correspondence: M. Kaya, MD, Department of Radiology, Gazi University School of Medicine, Ankara, Turkey, e-mail: radmustafakaya@hotmail.com; mustafaka@gazi.edu.tr

This article is available in open access under Creative Common Attribution-Non-Commercial-No Derivatives 4.0 International (CC BY-NC-ND 4.0) license, allowing to download articles and share them with others as long as they credit the authors and the publisher, but without permission to change them in any way or use them commercially. 
ported a high prevalence rate of dehiscence in lamina papyracea as $32 \%$.

Dehiscences in the bone structure are important for the intraorbital and intracranial spread of paranasal sinus infections [4]. It is also a facilitating condition for complications that can be seen during functional endoscopic sinus surgery (FESS) [15]. During FESS, various complications such as bleeding, blindness and even skull base defect can develop [1].

A properly performed computed tomography (CT) for paranasal sinuses provides detailed information about the sinonasal anatomy and its variations [2]. After a detailed investigation of the literature we tried to highlight the confusion about the terminological errors in publications about medial orbital wall discontinuities. In addition, we examined the frequency and localisations of medial orbital wall dehiscences in patients who underwent paranasal sinus $\mathrm{CT}$ examination with a pre-diagnosis of sinusitis but did not have active ethmoidal sinusitis.

\section{MATERIALS AND METHODS}

Five hundred paranasal sinus CT scans with pre-diagnosis of sinusitis and headache have been analysed by Picture Archiving and Communication Systems. Forty-eight patients with a history of surgery and/or major trauma and 26 patients with movement artefacts that impaired the medial orbital wall assessment were removed from the study sample. In addition, 311 patients with active sinusitis that could interfere with the evaluation of the medial orbital wall by affecting air-bone contrast were excluded from the study (Fig. 1). The study group consisted of 115 patients ( 59 males, 56 females) between 12 and 88 years of age who were previously thought to have had sinusitis but active ethmoid sinusitis was not detected by the $C T$ scan.

Imaging studies were performed in a private medical imaging centre between 07/2017 and 01/2018 using a GE brand IQ model spiral device with 32 detectors, and $130 \mathrm{kV}$ voltage and $80-120 \mathrm{mAs}$ values in accordance with the bone protocol. CT images were taken in the axial plane with a cross-section thickness of $2.5 \mathrm{~mm}$ and evaluated together with sagittal and coronal reformatted images.

This retrospective study involving human participants was in accordance with the ethical standards of the institutional and national research committee and with the 1964 Helsinki Declaration and its later amendments or comparable ethical standards. Informed consent was waived because of the retro-

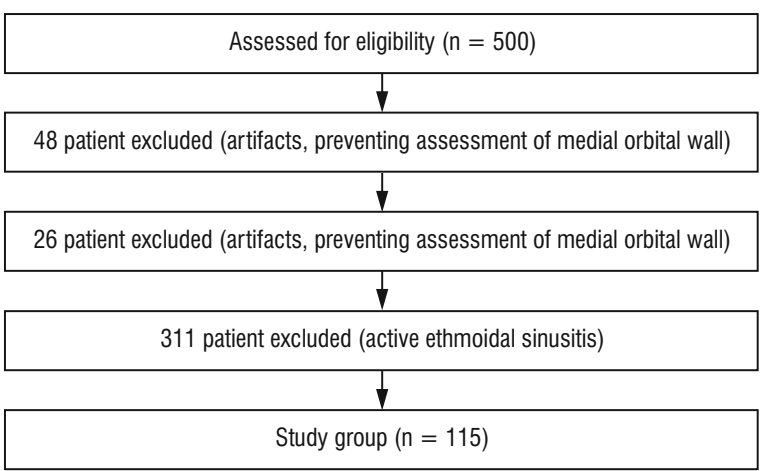

Figure 1. Flowchart shows study population and patient selection process.

spective nature of the study and the analysis used anonymous clinical data.

Two hundred-thirty orbital walls of 115 patients were examined in the axial plane and the discontinuity of bone density belonging to the bone structure between the orbital adipose tissue and ethmoid air was investigated. If bone discontinuities detected in the axial plane could be confirmed in the coronal or sagittal plane, they were accepted as a defect/gap. Findings were recorded for all patients, and cases were identified as defect/gap when two independent radiologists agreed. The medial orbital wall was divided into four as the anterior upper, anterior lower, posterior upper, posterior lower quadrant, and the distribution of dehiscence according to the quadrants was recorded.

Anterior and posterior dehiscences have been reported in the classification of dehiscence in literature and basal lamella separating the anterior and posterior ethmoid cells is considered as a border [14]. A classification of four quadrants, as we did in this report, has not been done before. The bone structures that constitute the medial orbital wall are the orbital face of the lacrimal bone, the frontal process of the maxillary bone, the LP of the ethmoid bone, and the corpus of the sphenoid bone.

Although the four-quadrant classification is not based on the bone margins, it can be said the anterior upper quadrant is formed by the frontal process of the maxillary bone, the upper $1 / 3$ part of the lacrimal bone and the anterior part of the lamina papyracea superior $1 / 2$ section. The anterior lower quadrant is formed by the lacrimal process of the maxillary bone, the lower $2 / 3$ part of the lacrimal bone and the anterior part of the LP inferior $1 / 2$ section. The 
posterior upper quadrant is formed by the posterior part of the LP superior $1 / 2$ section and part of the sphenoid bone corpus. The posterior lower quadrant is formed by the posterior part of the LP inferior $1 / 2$ section and part of the sphenoid corpus.

\section{Statistical analysis}

Patients with dehiscence were evaluated with the Spearman rho correlation coefficient test in terms of age, gender and dehiscence's being on the right or left side. The dehiscence frequencies according to the quadrants were analysed using the $\chi^{2}$ test. SPSS version 22 software (IBM Corporation NY, USA) was used when performing statistical analyses and the level of significance was set at alpha $=0.05$.

\section{RESULTS}

Bone defects were detected in 71 (30.9\%) of 230 orbital medial walls of 115 patients (59 male, $56 \mathrm{fe}-$ male). Some orbital medial walls had more than one defect and the total number of dehiscences was 108. A total of 108 dehiscences were detected, including 8 in the right anterior upper quadrant, 10 in the right anterior lower quadrant, 23 in the right posterior upper quadrant, 15 in the right posterior lower quadrant, 10 in the left anterior upper quadrant, 7 in the left anterior lower quadrant, 24 in the left posterior upper quadrant, and 11 in the left posterior lower quadrant (Fig. 2). Eight of the total orbital medial walls (3.5\%) had herniation of the orbital adipose tissue into the ethmoid sinus.

While no dehiscence was found in 60 patients, 16 patients had dehiscence on both the right and left sides. Dehiscence was observed in 23 patients on the right side and 16 patients on the left side.

When classified as right and left, there were 32 bone defects on the right orbital medial wall, while there were no bone defects on 83 orbital medial walls. While there were 39 bone defects on the left orbital medial wall, there were no bone defects on 76 orbital medial walls.

The mean age was 39.957, median age 39 years and the standard deviation was 15.871. The age distribution between men and women was homogeneous.

There was no significant relationship between age, sex, dehiscence on the right or left side, and the frequency of dehiscence ( $r$ in range of $0.074-0.211$ $p>0.05$ ). A statistically significant difference was found in the dehiscence distribution according to the quadrants $\left(\chi^{2}\right.$ test, $\mathrm{p}<0.05$; Tables $\left.1-4\right)$.

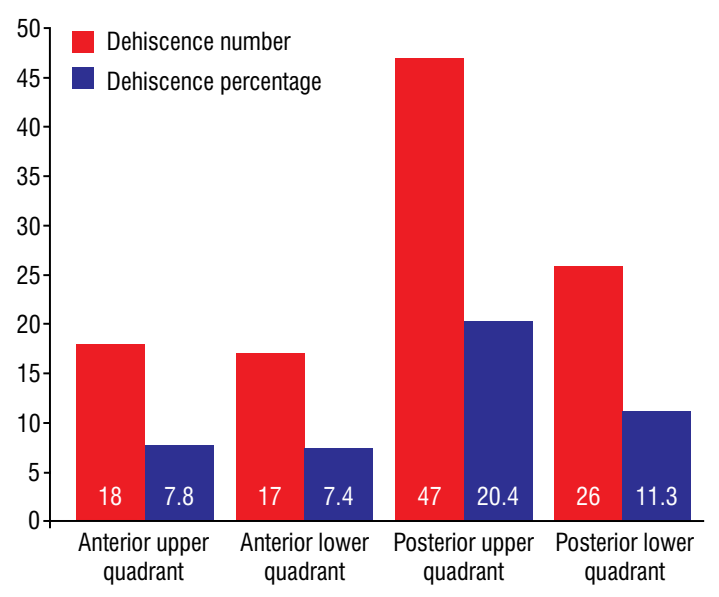

Figure 2. Distribution of dehiscences by quadrants.

Table 1. Prevalence of medial orbital wall dehiscences

\begin{tabular}{lcc}
\hline & \multicolumn{2}{c}{ Computed tomography images } \\
\cline { 2 - 3 } & $\mathbf{1 1 5}$ patients, $\mathbf{n}(\%)$ & $\mathbf{2 3 0}$ sides, $\mathbf{n}(\%)$ \\
\hline $\begin{array}{l}\text { Medial orbital wall } \\
\text { dehiscences }\end{array}$ & $55(47.8 \%)$ & $71(30.9 \%)$ \\
\hline
\end{tabular}

Table 2. The localisation of medial orbital wall dehiscences as right- and left-sided

\begin{tabular}{lcc}
\hline $\begin{array}{l}\text { Medial orbital } \\
\text { wall dehiscences }\end{array}$ & $\begin{array}{c}\text { Positive CT images } \\
\mathbf{1 1 5} \text { patients, } \mathbf{~}\end{array}$ & $\begin{array}{c}\text { Negative CT images } \\
\mathbf{1 1 5} \text { patients, } \mathbf{~}\end{array}$ \\
\hline Right & 32 & 83 \\
Left & 39 & 76 \\
\hline
\end{tabular}

CT — computed tomography; $\mathrm{n}$ - number of patients

\section{DISCUSSION}

The dehiscences in the medial orbital wall were firstly included in the German work which we can translate as the past and present of the University of Vienna Human Anatomy Museum written by Prof. Dr. Joseph Hyrtl in 1869. It is an inventory study of the museum; Hyrtl used the same term for bone defects in various anatomical structures in more than thirty locations in this work [8].

Prof. Dr. Emil Zuckerkandl, one of Hyrtl's students, who would be much more famous than Hyrtl himself in the future, also mentioned the existing dehiscences for many bones in his work titled "Normale und pathologische Anatomie der Nasenhöhle und ihrer pneumatischen Anhänge" published in 1882. Zuckerkandl used the term of dehiscence, which was also mentioned by 
Table 3. Bilateral and unilateral distributions of medial orbital wall dehiscences

\begin{tabular}{lcc}
\hline & $\begin{array}{c}\text { Right medial orbital wall positive } \\
\text { dehiscences CT images, } \mathbf{n}\end{array}$ & $\begin{array}{c}\text { Right medial orbital wall negative } \\
\text { dehiscences CT images, } \mathbf{n}\end{array}$ \\
\hline Left medial orbital wall positive dehiscences CT images, $n$ & $16(14 \%$ bilateral positive $)$ & $16(14 \%$ left unilateral positive) \\
Left medial orbital wall negative dehiscences CT images, $n$ & $23(20 \%$ right unilateral positive $)$ & 60 (52\% bilateral negative) \\
\hline
\end{tabular}

CT — computed tomography; $\mathrm{n}$ - number of patients

Table 4. Spearman rank correlation coefficient analysis between age, gender, side and dehiscence

\begin{tabular}{ccccc}
\hline Spearman's rho & Gender & Age & Right & Left \\
\hline Gender: & & & & \\
r & 1.000 & -0.74 & -0.133 & 0.036 \\
p & & 0.429 & 0.158 & 0.669 \\
Age: & & & & \\
r & & 1.000 & 0.087 & 0.059 \\
p & & & 0.353 & 0.533 \\
Right: & & & & \\
r & & 1.000 & 0.211 \\
p & & & 0.024 \\
Left & & & \\
r & & & & \\
p & & & & \\
\hline
\end{tabular}

Hyrtl before, for dehiscence in the medial orbital wall, stated that he saw this defect in various localisations of the medial orbital wall in 14 cases. Zuckerkandl also gave information about these dehiscences in the same work with very successful drawings [26].

American surgeon Howard A. Lothrop who studied at the University of Vienna for 2 years, stated that dehiscence in the frontal sinus as "the defects described as dehiscences by Zuckerkandl" in his article titled "The Anatomy and Surgery of the Frontal Sinus and Anterior Ethmoidal Cells", which was published in 1898. He stated that there was no frontal sinus dehiscence in his study, he found only two dehiscences in the LP in the 250 orbital walls of 125 cadavers, and this situation had no clinical significance [12].

The famous Hungarian otorhinolaryngology professor Adolf Onodi reported that there was an increase in the spread of sinus infections due to congenital and acquired bone defects, and he defined anterior frontal, posterior frontal, cribriform, maxillary, optic and sphenoid dehiscences in 1909 in his study of "oculo-orbital, intracranial and cerebral complications of paranasal sinus diseases". He emphasized the parallelism of these findings with Zuckerkandl, Mouret, Lindt, Castex, Cisneros, Jacques, Merlin, Gilmaertz and Spee and their importance in the spread of infection.
In the same article, he examined the thinness of the bones and stated that the cribriform plate was the thinnest bone, while drawing attention to the LP [17].

In 1911, Thomas J. Harris first used the term "Zuckerkandl dehiscence" in his article titled "Atypical mastoiditis - its cause, pathology, symptomatology and diagnosis" published in the journal of Laryngoscope [6]. However, he used this term (Zuckerkandl dehiscence) for dehiscences in the temporal bone and cited it as one of the spreading paths of the periostitis seen in latent mastoiditis.

Teatini et al. [23], in their article titled "Computed tomography of the ethmoid labyrinth and adjacent structures" performed in 1987, stated that dehiscences in LP were not frequent but their number increased after polyposis. In our opinion, this is one of the rare studies where the term dehiscence is used correctly. In the figure of the polyposis case presented in the study, dehiscences in the bone structure are clearly seen and herniation is not available.

In our literature review, we have noticed that the term of dehiscence is used synonymously with protrusion and herniation.

Meloni et al. [14] stated that they found a dehiscence rate of LP at $32 \%$ and only $6 \%$ had posterior ethmoid localisation in a radiological anatomy study involving 100 patients and emphasized the surgical importance of anatomic variations of ethmoid labyrinth and sphenoid sinus. Meloni et al. [14] reported the highest dehiscence rate of LP as 32\% in 1992 in the literature and this number is the closest value to our study. These dehiscences are $23 \%$ anterior, $6 \%$ posterior, and $2 \%$ affecting both. Meloni et al. [14] state that these defects are very common in very thin bone structures, which possibly occur as previous or already existing diseases, or sometimes develop spontaneously. In both cases, incomplete ossification or excessive pneumatisation is shown as the reason for this. In this study, Meloni et al. [14] reports bone dehiscences around the internal acoustic canal, maxillary nerve, and Vidian nerve as well as the dehiscences in LP. The reason for the high dehiscence 
rates is probably because the researchers interpret the excessive thinning of the bone plate as a dehiscence. Although there are no patients with active ethmoidal sinusitis in our study group, previous sinusitis can also cause excessive thinning of the bone plate, which we interpret as dehiscence.

Moulin et al. [16] reported that six dehiscences, which they found in the 783 CT scans, always involved the external wall of the ethmoid bulla and the posterior part of the ethmoid bone was preserved. Similar to previous literature, they stated that there was no dehiscence in the posterior of basal lamella [16]. While Moulin et al. [16] explained the dehiscence rate as $0.8 \%$, they stated that they might be confused with infectious, tumoural or post-traumatic lesions. This implies that all six patients had a fatty mass protrusion view associated with orbital fat through a gap. It was reported that in one patient, dehiscence affected the lacrimal bone; in no case the ethmoid bulla was completely filled. Again, in the same study, the term 'gap' was used several times instead of dehiscence.

The embryogenesis of congenital LP dehiscences is uncertain. Since ethmoid cells are formed by the invagination of the olfactory pit epithelium, the holes in the LP can occur as the olfactory pit epithelium goes beyond the lateral limit of the facial embryonic mesenchyme (overextension). However, cadaveric studies and the bulge towards the medial, which Zuckerkandl defined in LP, conflict with this explanation [16].

Han et al. [5] prefer the term 'prolapse' instead of dehiscence because $70 \%$ of the orbital adipose tissue herniations have displacement or bowing in the bone. In the same study, although it was not statistically significant, it was stated that the age-related degeneration or subclinical minor traumas may be plausible explanation in congenital dehiscence or orbital medial bone wall weaknesses, by drawing attention to the frequency rate increasing with age [5].

In a major review article called "Ophtalmic complications of the endoscopic sinus surgery", Bhatti and Stankiewicz [1] shares the illustration of cutting by aspirating the medial rectus muscle into the sinus although a powered cutting instrument does not enter into the orbita in a dehiscence case without an apparent herniation in the orbital medial wall and stated that the cutting surgical tool can cause damage to the medial rectus muscle without entering the orbita in dehiscence cases [1].
In the case report in which the dehiscence in LP was explained with magnetic resonance findings, Makariou et al. [13] stated that herniation containing orbital adipose tissue and medial rectus muscle accompanying the defect in LP caused complaints of diplopia and blurred vision and they reported that it would be beneficial to know the presence of this anatomic malformation in order to decrease the risks for complications such as globe and extraocular muscle damage, haematoma, cerebrospinal fluid leak, intracranial infection or intracranial injury during FESS [13].

In the study in which Meyers and Valvassori [15] evaluated the anatomical variations of the paranasal sinus with the surgical perspective, they suggest that LP was firstly examined from the anterior to the posterior for proper defect in terms of critical surgical information obtained from axial CT images. Meyers and Valvassori [15] use the terms 'protrusion', 'herniation' and 'dehiscence' in similar meanings in the study in which they stated that they found two herniations in 400 patients [15].

Kitaguchi et al. [9] stated that they found 1.4\% dehiscence in their study on 315 patients and that all dehiscences were at the level of anterior ethmoid sinus. Seeley et al. [20] reported a bilateral anterior LP dehiscence case in 2010.

In a case report published by Lim et al. [11] in 1999, they stated that that the CT findings in 57-year-old woman with the complaints of nasal obstruction, postnasal discharge and clear rhinorrhoea and without a history of previous nasal surgery or trauma was reported as normal by the radiologist and, in the subsequent evaluation, herniating orbital fat and part of medial rectus muscle could be clearly seen on the medial orbital wall. Lim et al. [11] stated that lamina papyracea dehiscences and accompanying orbital adipose tissue protrusions were previously reported to occur due to congenital or posttraumatic causes, but protrusion without a gap in the medial orbital wall was reported for the first time. In our study, one patient had protrusion bordered by bone structure without gap in the medial orbital wall.

After the widespread use of $\mathrm{CT}$, detailed imaging of the ethmoid bone has increased especially and also publications about the topic have increased in the literature in recent years. The cases in which the orbital contents have shown herniation into the ethmoid sinus have been generally considered as dehiscence. However, it has been observed that the presence of 
dehiscence has not met the requirement of a herniation in dissection studies since Lothrop [12].

In some publications over the past 20 years, dehiscences on the medial wall of the orbita have been defined as "Zuckerkandl dehiscence" [3, 7, 19, 21, 22].

In the case report "Concomitant bilateral orbital and brain abscess" conducted by Huang et al. [7] in 2003, they referred to Zuckerkandl's own work written in 1892 and stated that dehiscences in LP were also called the Zuckerkandl dehiscence.

In 2008, Shoja et al. [21] described the scientist's life and studies in the article "Emil Zuckerkandl", and they said that the fissures in the ethmoid bone were called Zuckerkandl dehiscence.

In 2014, a paediatric case presentation titled "Bilateral orbital complications of paediatric rhinosinusitis" by Singh et al. [22] and another article "Imaging for Headache: What the neuroradiologist looks for" by Bricker and Stultz [3], it was reported that dehiscences in lamina papyracea were known as the Zuckerkandl dehiscence.

In 2014, Ozdemir and Elmas [19] carried the phrase Zuckerkandl dehiscence to the title of their article as "Recurrent sinusitis and periorbital cellulitis secondary to congenital Zuckerkandl dehiscence".

As can be seen, there is confusion in the medical literature in terms of both the distinction between dehiscence and herniation, and naming the defects in lamina papyracea as Zuckerkandl dehiscence.

In the literature, we have noticed that different authors use the terms of dehiscence, protrusion, herniation, prolapse, or even ingression for the herniation of orbital content into the ethmoid sinus [24]. In our opinion, the dehiscences that are not accompanied by orbital adipose tissue herniation in LP and those accompanied by orbital adipose tissue herniation are different entities (Figs. 3-5). Although the subject of which entity is more risky during FESS needs to be investigated; the presence of herniation accompanying the dehiscence can be a more risky situation in $\mathrm{LP}$, which is mostly a thin structure, compared to the presence of only dehiscence. Therefore, we think that defining the herniation that accompanies dehiscence as only a dehiscence is an inadequate explanation.

Lamina papyracea dehiscences observed on $\mathrm{CT}$ are not uncommon, but misinterpretation is possible depending on quality of $\mathrm{CT}$ images. We agree with Meloni et al. [14] that there is no difference in terms of the vulnerability of the bone that is thin enough to be interpreted as a true dehiscence or

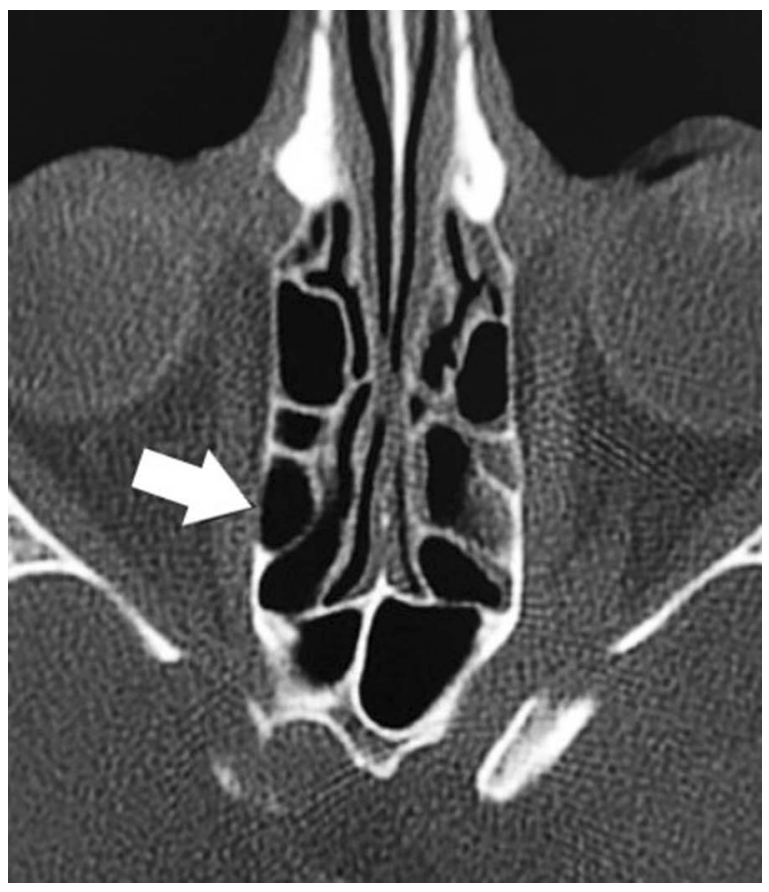

Figure 3. Dehiscence of medial orbital wall on axial plane computed tomography (most likely incomplete ossification).

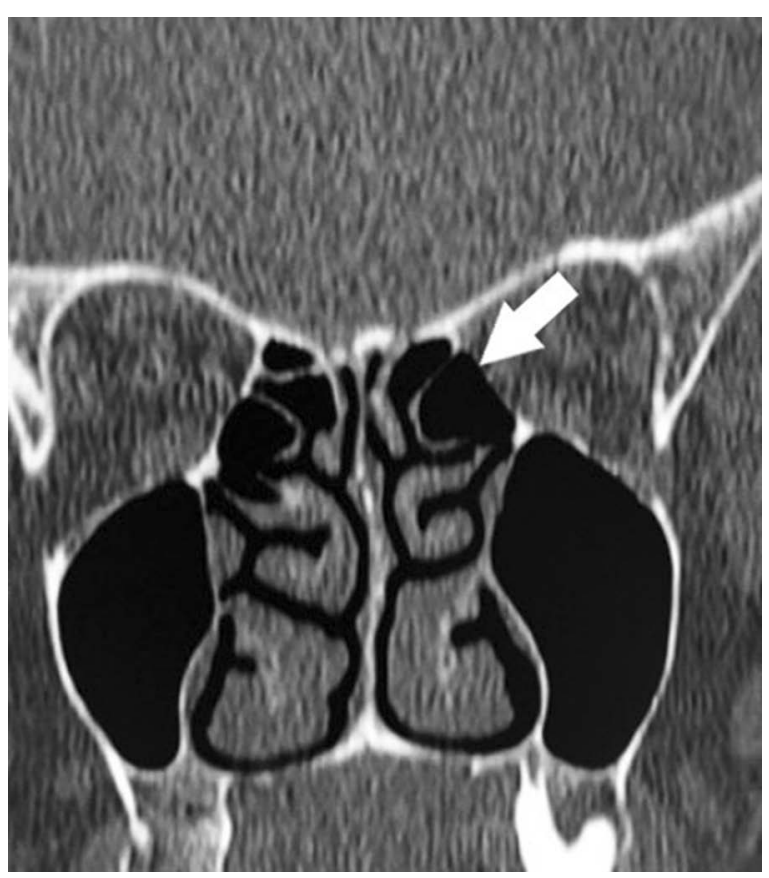

Figure 4. Dehiscence of medial orbital wall on coronal plane computed tomography (most likely incomplete ossification).

dehiscence in CT. The point we want to emphasize is that the introduction of orbital content into the ethmoid sinus, which can be expressed in protrusion/ 


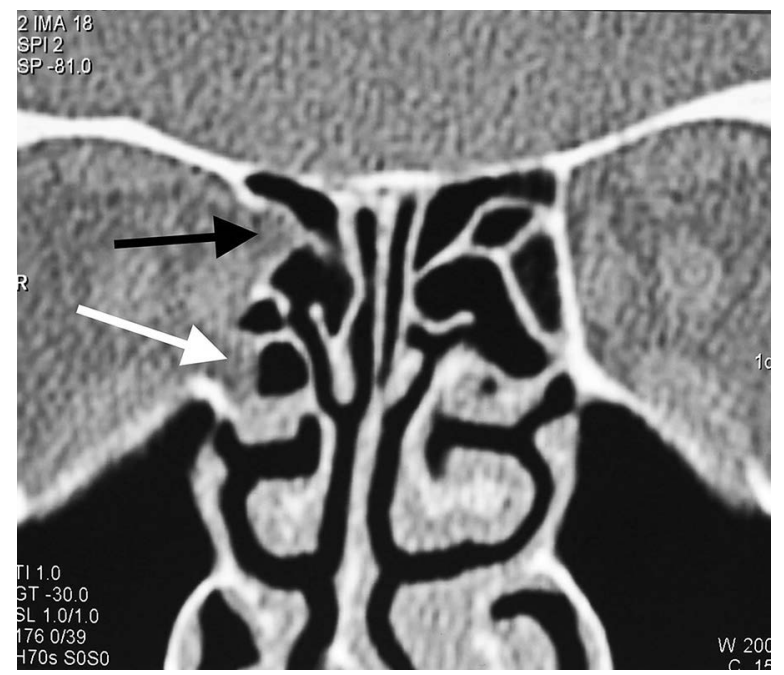

Figure 5. Orbital adipose tissue herniated from two separate localisations to the ethmoid sinus; black arrow - orbital adipose tissue herniated from superior; white arrow — orbital adipose tissue herniated from inferior.

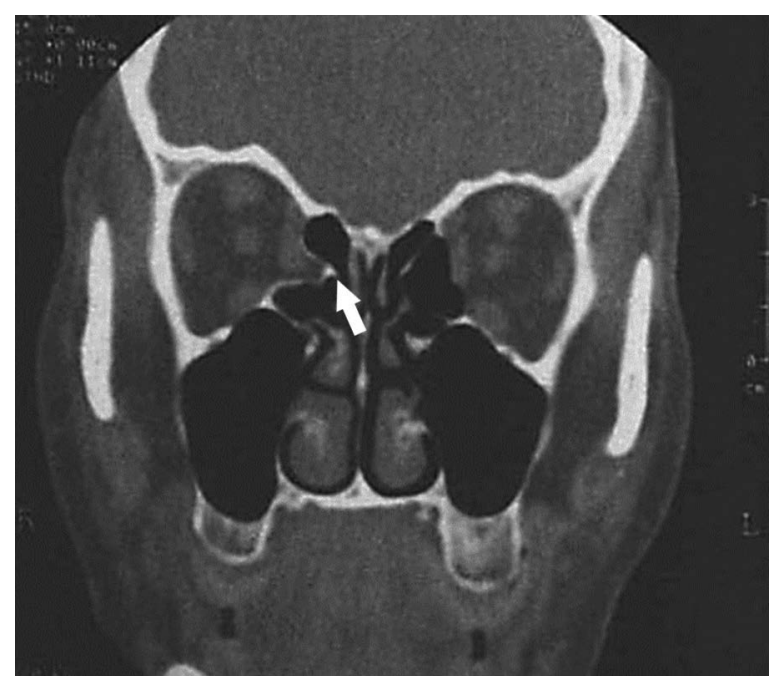

Figure 6. Bone plus orbital fat protrusion without dehiscence on the medial orbital wall, which Lim defined in 1999 and we observed in one case.

prolapse/herniation, or otherwise, is not the same thing with the situation that does not accompany such changes and has been called dehiscence since 1869. In other words, the situation that we express as dehiscence in lamina papyracea does not always occur with herniation.

Therefore, using the term "dehiscence" for gaps and defects while interpreting the images and using the term "herniation" for the entry of the orbital content into the ethmoid sinus accompanied by de- hiscence will eliminate the confusion of situations. In addition, the terms of "protrusion" or "bone protrusion" or "bone and orbital fat protrusion" will be more explanatory for the definition of protrusion without dehiscence in the medial orbital wall, which was reported by Lim et al. [11], and such an image is already seen in one of our patients (Fig. 6). In our opinion, calling the LP dehiscence 'Zuckerkandl dehiscence' will be a preference that may cause misunderstandings rather than specifying the situation.

In our study, the rate of dehiscence (loss of bone continuity) without herniation was found to be higher than in most of the research. There may be three explanations for this high rate of dehiscence. First, the inability to distinguish the low-density bone structure below a certain thickness in our CT examinations. Second, the excessive thinning of the medial orbital wall caused by the previous sinusitis in our study group. Third, the fact that most of the research only defines orbital adipose tissue herniations as dehiscence may be the explanation for our high rate of dehiscence. It was thought that these interpretations could be checked by microdissection of samples with dehiscence in cadaver specimens undergoing $\mathrm{CT}$.

\section{CONCLUSIONS}

As a result, we believe that radiologists should investigate the presence of medial orbital wall dehiscence whether there is a herniation or not, during the interpretation of paranasal sinus $\mathrm{CT}$, and they should pay strict attention to the correct use of the words "herniation, dehiscence/gap, protrusion" in their comments and studies.

\section{Conflict of interest: None declared}

\section{REFERENCES}

1. Bhatti M, Stankiewicz J. Ophthalmic complications of endoscopic sinus surgery. Surv Ophthalmol. 2003; 48(4): 389-402, doi: 10.1016/s0039-6257(03)00055-9.

2. Bolger WE, Butzin CA, Parsons DS. Paranasal sinus bony anatomic variations and mucosal abnormalities: $\mathrm{CT}$ analysis for endoscopic sinus surgery. Laryngoscope. 1991; 101(1 Pt 1): 56-64, doi: 10.1288/00005537-199101000-00010, indexed in Pubmed: 1984551.

3. Bricker A, Stultz T. Imaging for headache: what the neuroradiologist looks for. Otolaryngol Clin North Am. 2014; 47(2): 197-219, doi: 10.1016/j.otc.2013.10.009, indexed in Pubmed: 24680489.

4. Dankbaar JW, van Bemmel AJM, Pameijer FA. Imaging findings of the orbital and intracranial complications of acute bacterial rhinosinusitis. Insights Imaging. 2015; 
6(5): 509-518, doi: 10.1007/s13244-015-0424-y, indexed in Pubmed: 26253983.

5. Han M, Chang K, Min Y, et al. Nontraumatic prolapse of the orbital contents into the ethmoid sinus: Evaluation with screening sinus CT. Am J Otolaryngol. 1996; 17(3): 184-189, doi: 10.1016/s0196-0709(96)90058-7.

6. Harris TJ. Atypical mastoiditis - its cause, pathology, symptomatology and diagnosis. Laryngoscope. 1911; 21(7): 775-783, doi: 10.1288/00005537-191107000-00005.

7. Huang SF, Lee TJ, Lin KL. Concomitant bilateral orbital and brain abscesses--unusual complications of pediatric rhinosinusitis. Chang Gung Med J. 2005; 28(1): 51-55, indexed in Pubmed: 15804149.

8. Hyrtl J. Vergangenheit und Gegenwart des Museums für Menschliche Anatomie an der Wiener Universität. Wilhelm von Braumüller, Wien 1869.

9. Kitaguchi Y, Takahashi Y, Mupas-Uy J, et al. Characteristics of dehiscence of lamina papyracea found on computed tomography before orbital and endoscopic endonasal surgeries. J Craniofac Surg. 2016; 27(7): e662-e665, doi: 10.1097/ SCS.0000000000003005, indexed in Pubmed: 27536917.

10. Lang J, Schäfer K. [Ethmoidal arteries: origin, course, regions supplied and anastomoses]. Acta Anat (Basel). 1979; 104(2): 183-197, indexed in Pubmed: 442972.

11. Lim JC, Hadfield PJ, Ghiacy S, et al. Medial orbital protrusion: a potentially hazardous anomaly during endoscopic sinus surgery. J Laryngol Otol. 1999; 113(8): 754-755, doi: 10.1017/s0022215100145116, indexed in Pubmed: 10748855.

12. Lothrop HA. IV. The anatomy and surgery of the frontal sinus and anterior ethmoidal cells. Ann Surg. 1898; 28(5): 611-638, indexed in Pubmed: 17860649.

13. Makariou E, Patsalides A, Harley E. Dehiscence of the lamina papyracea: MRI findings. Clin Radiol Extra. 2004; 59(5): 40-42, doi: 10.1016/j.cradex.2003.12.003.

14. Meloni F, Mini R, Rovasio S, et al. Anatomic variations of surgical importance in ethmoid labyrinth and sphenoid sinus. A study of radiological anatomy. Surg Radiol Anat. 1992; 14(1): 65-70, doi: 10.1007/BF01628046, indexed in Pubmed: 1589850.

15. Meyers RM, Valvassori G. Interpretation of anatomic variations of computed tomography scans of the sinuses: a surgeon's perspective. Laryngoscope. 1998; 108(3): 422-425, doi: 10.1097/00005537-199803000-00020, indexed in Pubmed: 9504618.
16. Moulin G, Dessi $P$, Chagnaud C, et al. Dehiscence of the lamina papyracea of the ethmoid bone: CT findings. Am J Neuroradiol. 1994; 15(1): 151-153, indexed in Pubmed: 8141047.

17. Onodi A, Goldstein MA. The oculo-orbital, intracranial and cerebral complications of diseases of the nasal accessory sinuses. Laryngoscope. 1909; 19(11): 801-822, doi: 10.1288/00005537-190911000-00001.

18. Onodi A. Die Stirnhöhle: Beiträge Zur Topographisch - chirurgischen Anatomie Und Zur Lehre Von Den Erkrankungen Der Stirnhöhle. Alfred Hölder, Wien 1909.

19. Ozdemir O, Elmas B. Recurrent Sinusitis and Periorbital Cellulitis Secondary to Congenital Zuckerkandl Dehiscence. MOJ Immunology. 2014; 1(5), doi: 10.15406/ moji.2014.01.00027.

20. Seeley MJ, Waterhouse DR, Shetty S, et al. Boundary issues: a case of nontraumatic bilateral dehiscence of the lamina papyracea. Arch Otolaryngol Head Neck Surg. 2010; 136(1): 88-89, doi: 10.1001/archoto.2009.196, indexed in Pubmed: 20083785.

21. Shoja MM, Tubbs RS, Loukas $M$, et al. Emil Zuckerkandl (1849-1910): anatomist and pathologist. Ann Anat. 2008; 190(1): 33-36, doi: 10.1016/j.aanat.2007.09.001, indexed in Pubmed: 18342140.

22. Singh SK, James $E$, Sabarigirish $K$, et al. Bilateral orbital complications of paediatric rhinosinusitis. Med J Armed Forces India. 2014; 70(1): 68-72, doi: 10.1016/j. mjafi.2012.11.015, indexed in Pubmed: 24623951.

23. Teatini G, Simonetti G, Salvolini U, et al. Computed tomography of the ethmoid labyrinth and adjacent structures. Ann Otol Rhinol Laryngol. 2016; 96(3): 239-250, doi: 10.1177/000348948709600301.

24. Wang Y, Zhang YJ, Zhu HH. [Effect of lamina papyracea ingression on orbito-ocular complications after functional endoscopic sinus surgery]. Zhonghua Er Bi Yan Hou Tou Jing Wai Ke Za Zhi. 2016; 51(8): 589-592, doi: 10.3760/ cma.j.issn.1673-0860.2016.08.006, indexed in Pubmed: 27625128.

25. Yang YX, Lu QK, Liao JC, et al. Morphological characteristics of the anterior ethmoidal artery in ethmoid roof and endoscopic localization. Skull Base. 2009; 19(5): 311-317, doi: 10.1055/s-0028-1115323, indexed in Pubmed: 20190940.

26. Zuckerkandl E. Normale und pathologische Anatomie der Nasenhöhle und ihrer pneumatischen Anhange. DMW - Deutsche Medizinische Wochenschrift. 2009; 8(23): 328-329, doi: 10.1055/s-0029-1196610. 